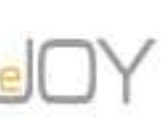

Special Issue on 3rd International EUREFE Congress

\title{
Türkiye'de Döviz Kurundaki Değişimlerin İthal Girdi Maliyeti Üzerinden Üretici Fiyatlara Etkisi ${ }^{1}$
}

\section{Effect of Changes in Exchange Rate on Producer Prices through Imported Input Cost}

\author{
Özcan KARAHAN, Bandırma Onyedi Eylül Üniversitesi, Türkiye, okarahan@bandirma.edu.tr \\ Orcid No: 0000-0002-1179-2125 \\ Ali Selçuk GENCÜR, Bandırma Onyedi Eylül Üniversitesi, Türkiye, agencur@bandirma.edu.tr \\ Orcid No: 0000-0001-8957-6783
}

Öz: Uluslararası sermaye hareketlerinin hızla artırması ile birlikte döviz kurları gelişmekte olan ülkelerde fiyat seviyesini etkileyen önemli bir faktör haline gelmiştir. Öyle ki, bu süreçte döviz kurundaki dalgalanmalar ithal edilen girdi maliyetleri üzerinde oluşturduğu etkiler yolu ile yurt içi fiyat seviyesinde ciddi istikrarsızlıklara yol açmıştır. Gelişmekte olan ülkelerde üretim sürecinde kullanılan sermaye ve ara mallarının büyük bir kısmı yurt dışından ithal edilmektedir. Böylece kur değisşimleri hızla yurt içindeki üretim malları fiyatlarına yanslyarak fiyat istikrarını hedefleyen merkez bankası politikalarının etkinliğini azaltmaktadır. Literatürde kur geçişkenliği sürecine ilişkin yapılan bu tespitler araştırmamı kapsamında Türkiye ekonomisi örneğinden hareketle analiz edilmiştir. Bu çerçevede kur değişimlerinin üretim mall fiyatları üzerinde yarattı̆̆ etkiler aylı veriler kullanılarak 2006 ile 2017 yılları arasındaki dönem için incelenmiştir. Ampirik yöntem olarak Etki-Tepki Fonksiyonu (Impulse Response Function) ve Varyans Ayrlşttrması (Variance Decomposition) tekniklerini içeren VAR (Vector Autoregression) modeli kullanılmıştır. Sonuçlar, kur değişimlerinin ithal girdi maliyetleri üzerinden üretim malları fiyatlarını etkilediğini göstermiştir. Bu durum Türkiye'de uygulanmakta olan Enflasyon Hedeflemeli Para Politikasının başarısını olumsuz yönde etkileyecek çok önemli riskler yaratmaktadır. Bunun için Türkiye'de para politikası uygulamaları belirlenirken döviz kurundaki değişimleri kontrol edebilecek şekilde tasarlanmasına büyük bir ihtiyaç vardır.

Anahtar Sözcükler: Döviz Kuru, Fiyatlar Genel Seviyesi, Türkiye, VAR Modeli

JEL Siniflandirması: F31, E31, C22

Abstract: With the increase in international capital movements, exchange rates have become an important factor affecting the price level in developing countries. In this process, the changes in the exchange rate cause serious instability in the price level through the effects on imported input costs. Imported capital and intermediary goods in developing countries are the most important inputs of the production goods process. Therefore, exchange rate changes are rapidly reflected in the prices of domestic production goods, thus reducing the effectiveness of central bank policies aiming price stability. In the literature, these determinations made regarding the exchange rate passthrough process have been investigated departing from the example of our research within the scope of Turkey's economy. In this context, the effects of exchange rate changes on prices of production goods were analysed for the

\footnotetext{
${ }^{1}$ Bu çalışmada, Balıkesir Üniversitesi Sosyal Bilimler Enstitüsü İktisat Anabilim Dalı’nda, Prof. Dr. Özcan Karahan danışmanlığında Ali Selçuk Gencür tarafindan yürütülen “Türkiye'de Döviz Kuru Geçişkenliği” başlıklı doktora tezinden yararlanılmıştır.

Makale Gecmiși / Article History

Başvuru Tarihi / Date of Application : 25 Aralık / December 2019

Kabul Tarihi / Acceptance Date : : 4 Şubat / February 2020
} 
Karahan, Ö., Gencür, A., S., / Journal of Yasar University, 2020, Special Issue on 3rd International EUREFE Congress, 48-65

period between 2006 and 2017 by using monthly data. As an empirical method, Vector Autoregression (VAR) method including Impulse Response Function and Variance Decomposition techniques were used. The results show that exchange rate changes affect the prices of production goods over imported input costs. This situation created major risks that will adversely affect the success of the Inflation-Targeted Monetary Policy being implemented in Turkey. Therefore, there is a great need to control the changes in the exchange rate while designing monetary policy instruments in Turkey.

Keywords: Exchange Rate, General Price Level, Turkey, VAR Model

JEL Classification: F31, E31, C22

\section{Giriș}

Ekonomik globalleşmenin hızla artması ile birlikte uluslararası sermaye hareketlerinin hacmi büyük boyutlara ulaşmıştır. Böylece uluslararası sermaye hareketlerinin yarattığı dış şoklara karşı ülke ekonomileri aşırı duyarlı hale gelmiştir. Öyle ki, günümüzde birçok makroekonomik göstergenin oluşumunda küresel düzeydeki değiş̧imler önemli derecede rol oynamaktadır. Bu süreçte döviz kurlarındaki değişimler ülkelerin iç ekonomik gelişmelerini etkileyen önemli bir dinamik olarak ortaya çıkmıştır. Döviz kurundaki değişimler özellikle fiyat seviyesinde önemli dalgalanmalara neden olabilmektedir. Döviz kuru seviyesindeki değişimler çeşitli kanallarla ülkedeki fiyat düzeyini etkileyebilmektedir. "Döviz Kuru Geçişkenliğgi” (Exchange Rate Passthrough) kavramı ile ifade edilen bu süreç enflasyonun dinamiklerini açıklamak için oluşturulan modellerde çok önemli bir yer bulmuştur.

Yukarıda belirlendiği şekilde kur seviyesindeki dalgalanmalar fiyatları etkileyen önemli bir faktör haline dönüşürken, bu durum hiç şüphesiz fiyat istikrarını hedefleyen merkez bankalarının para politikası uygulamalarını da yakından etkilemiştir. Özellikle merkez bankalarının son dönemde uyguladıkları enflasyonla mücadele politikaları döviz kurlarında yaşanan değişimlere oldukça duyarlı olmaya başlamıştır. Gerçekten de enflasyon hedeflemeli para rejiminin uygulandığı ülkelerde kur geçişkenliği olgusunun büyük önem kazandığı görülmektedir. Öyle ki, ampirik çalışmaların büyük bir bölümü döviz kuru geçişkenliğinin derecesi ile enflasyon hedeflemeli istikrar programının etkinliği arasında sıkı bir ilişki olduğunu ortaya koymuştur. Bunun sonucunda döviz kurlarındaki değişimlerin fiyatlara geçişkenliğinin büyük olduğu ülkelerde enflasyon hedeflemeli istikrar programının uygulamasında güçlükler yaşanmaya başlamıştır.

Türkiye uzunca bir süre sabit döviz kuru sistemine dayalı olarak para politikası stratejisini tercih etmiştir. Ancak, 2001 yılından sonra örtük biçimde, 2006 yılından itibaren ise açık bir şekilde Enflasyon Hedeflemeli İstikrar Programı uygulanmaya başlamıştır. Böylece, enflasyon oranının kontrol altında tutulması dolayısı ile fiyat istikrarı temel hedef olarak seçilmiştir. 
Ayrıca bu amaç çerçevesinde faiz oranları önemli bir politika aracı olarak kullanılırken döviz kuru ise serbest dalgalanmaya bırakılmıştır. Buna göre faiz oranları ile toplam talep kontrol altına alınarak fiyatlar genel seviyesi yönetilmeye çalışılmıştır. Ancak döviz kuru geçişkenliğinin yüksek olduğu durumlarda serbest dalgalanmaya bırakılan kur hareketleri fiyatlar genel seviyesinde büyük istikrarsızlıklar yaratma potansiyeli taşımaktadır. Böylece kur geçişkenliği olgusu Türkiye'de Enflasyon Hedeflemeli İstikrar Programı'nın etkin bir biçimde uygulanmasını engelleyecek önemli bir risk yaratma potansiyeline sahiptir.

Yukarıda ortaya konan tespitlerden hareketle, çalışmamızın amacı Türkiye'de yaşanan kur geçişkenliği sürecini analiz ederek uygulanmakta olan Enflasyon Hedeflemeli İstikrar Politikalarının etkinliğine ilişkin yarattığı riski belirlemektir. Bu çerçevede kur değişimlerinin ithal girdi maliyetleri yolu ile fiyatlar genel seviyesi üzerinde yarattığı etkiler 2006 ile 2017 yılları arasındaki dönem için Vektör Otoregresif (Vector Autoregressive -VAR) yöntemi kullanılarak analiz edilmiştir. Ampirik bulgular, özellikle 2006 tarihinden itibaren açık bir biçimde uygulanan, Enflasyon Hedeflemeli İstikrar Programı'nın etkinliğine ilişkin çok önemli çıkarımlar yapmamıza imkân vermiştir. Çalışmada kur değişimlerinin fiyatlar genel seviyesi üzerinde, ithal girdi maliyetleri yolu ile yarattığı etki açıkça ortaya konmuştur. Bunun yanında Türkiye Cumhuriyeti Merkez Bankası' nın (TCMB) Enflasyon Hedeflemeli İstikrar Programını uygularken karşı karşıya kaldığı riskleri yönetmek için uygulaması gereken politikalara ilişkin çeşitli çıkarımlar yapılmıştır. Böylece araştırma sonucunda elde edilen bulgular ve buna dayalı olarak geliştirilen önerilerle TCMB'nin Enflasyon Hedeflemeli İstikrar Programı çerçevesinde gerçekleştirdiği politikaların etkinleştirilmesine katkı sunulması hedeflenmektedir.

\section{Literatür Araştırması}

Döviz kurundaki değişimlerin yurt içi fiyatlarda artış yaratarak enflasyona yol açma süreci iktisat literatüründe "Döviz Kuru Geçişkenliği” (Exchange Rate Pass-through) kavramı ile ifade edilmektedir. Görüldüğü gibi bu kavram ulusal paranın yabancı paralar ile değişim oranında meydana gelen bir dalgalanmanın yurtiçi enflasyon oranı üzerinde yarattığı etkilere işaret etmektedir. Literatür incelendiğinde bu sürecin dinamiklerini anlamaya yönelik birçok araştırmanın yapıldığı görülmektedir. Bu çalışmalar sonucunda, kullanılan veri ve ekonometrik yöntemlerdeki farklılık nedeni ile kur geçişkenliğinin derecesine ilişkin değişik bulguların elde edildiği de görülmektedir. Ayrıca araştırma yapılan ülkelerde uygulanan iktisat politikalarındaki farklılıkların ortaya çıkardığı değişimlerde kur geçişkenliği derecesinin belirlenmesinde farklı sonuçların bulunmasına yol açabilmektedir. Bu bölümde literatürde elde edilen söz konusu sonuçlar gelişmiş ülke ve gelişmekte olan ülke koşulları çerçevesinde yapılan 
Karahan, Ö., Gencür, A., S., / Journal of Yasar University, 2020, Special Issue on 3rd International EUREFE Congress, $48-65$

çalışmalar bağlamında ortaya konmuştur. Ayrıca bu bölümün son kısmında Türkiye’ye yönelik çalışmalarda gözden geçirilmiştir.

Kur geçişkenliği sürecini araştırmaya yönelik gerçekleştirilen ilk çalışmalarda kurlardaki dalgalanmaların dış ticaret fiyatları üzerinde yarattığı etkiler daha çok ele alınmıştır. Böylece döviz kuru geçişkenliği süreci, döviz kurundaki bir birimlik değişmenin ithal ürünlerin ulusal para cinsinden yurt içindeki satış fiyatlarında yol açtığı dalgalanma ile ortaya konmuştur. Daha sonra ise kur geçişkenliğinin ifade ettiği süreç daha geniş bir çerçevede ele alınarak diş ticaret fiyatlarındaki değişimin hem üretici ve hem de tüketici fiyatlar genel seviyesi üzerinde yarattığı etkiler bağlamında incelenmiştir. Başka bir ifade ile literatürde ilk çalışmalar döviz kuru değişim oranının ithalat fiyatlarına yaptığı etkiler çerçevesinde incelenirken daha sonra üretici ve tüketici fiyatları üzerinde oluşturduğu etkiler modele katılarak analiz daha da geliştirilmiştir. Buna göre kur değişimlerinin yurt içi fiyatlara etkisi çerçevesinde bir kısım çalışma yurt içi Tüketici Fiyat Endeksini (TÜFE) esas alırken diğer bir grup çalışma ise daha doğrudan etkileri yansıttığı için yurt içi Üretici Fiyat Endeksini (ÜFE) esas almıştır.

Literatür incelendiğinde gelişmiş ülkeler üzerinde gerçekleştirilen çalışmalar da döviz kuru geçişkenliği sürecinin dinamiklerine ilişkin önemli bazı tespitlerin yapıldığı görülmektedir. Campa ve Goldberg (2002) kurlardan yurt içi fiyatlara geçiş etkisini 25 OECD ülkesi üzerinde 1975 ile 1999 yılları arasındaki dönem için analiz etmiştir. Bulgular kısa dönemde kur değişimlerinden fiyatlara geçiş etkisinin uzun döneme göre düşük olduğunu göstermiştir. Ancak uzun dönemde kur geçişkenliği artsa da tam bir kur geçişkenliğin den söz etmek mümkün değildir. Bailliu ve Fujii (2004) döviz kuru değişiklerinin yurt içi fiyatlarına geçiş etkisini 11 sanayileşmiş ülke için 1977 ve 2001 yıllarına ait verileri kullanarak panel analiz yöntemi ile tahmin etmiştir. Sonuçlar ithalat, üretici ve tüketici fiyat indekslerine döviz kuru geçiş etkisinin zaman içinde azaldığını göstermiştir. Bu bulguların ortaya çıkmasında ilgili ülkelerde uygulanan para politikasının sebep olduğu düşük enflasyon ortamının büyük rol oynadığı belirlenmiştir. An (2006) Amerika Birleşik Devletleri, Japonya, Kanada, İtalya, İngiltere, Finlandiya, İsveç ve İspanya'dan oluşan 8 ülkede kur geçişkenliği sürecini VAR yöntemini kullanarak analiz etmiştir. Çalışmada 1976 ile 2005 yılları arasındaki aylık verilerden yararlanılmıştır. Sonuçlar kur geçişkenlik etkisinin gerek büyüklük gerekse hız bazında zaman içinde zayıfladığını belirlenmiştir. Son dönemde Liu ve Liu (2014) Amerika Birleşik Devletleri, Japonya ve Çin ekonomilerinde kur değişimlerinin tüketici fiyatları üzerindeki asimetrik etkilerini incelemiştir. Bu çerçevede Hata Düzeltme Modeli (Error Correction Model) kullanılarak 1994 ile 2010 yılları arasındaki veriler analiz edilmiştir. Bulgular hiçbir ülkede kur 
Karahan, Ö., Gencür, A., S., / Journal of Yasar University, 2020, Special Issue on 3rd International EUREFE Congress, $48-65$

değişimlerinin yurt içi fiyatlara tam olarak yansımadığını göstermiştir. Kiliç (2016) Almanya, Birleşik Krallık, Kanada, Almanya, Avustralya ve Amerika Birleşik Devletleri'nde 1975 ile 2009 yılları arasındaki çeyreklik verilerden yararlanarak kur geçişkenliği sürecini araştırmıştır. Elde edilen veriler kur değişimleri ile fiyat değişimleri arasında doğrusal olmayan bir ilişki olduğunu göstermiştir.

Gelişmekte olan ülkeler üzerine yoğunlaşan çalışmalarda da kur geçişkenliği sürecinin büyüklüğü ve zaman içinde gelişimine ilişskin önemli tespitlerin yapıldığı görülmektedir. Ayrıca, dış kaynaklara bağımlılık olgusu, iktisat politikalarının yarattığı etkiler ve zaman içinde yaşanan yapısal dönüşümlerde bu ülkelerde kur değişimlerinin yurt içi fiyat seviyesine geçiş derecesini etkileyebilmektedir. Barhoumi (2006) döviz kurunun ithalat fiyatlarına geçiş etkisini gelişmekte olan yirmi dört ülkeden oluşan bir grup üzerinde analiz etmiştir. Analiz dönemi 1980 ve 2003 yılları arasındaki süreci kapsamıştır. Modeldeki değişkenler nominal döviz kuru, rakip ürün fiyatları, ihracatçı maliyetleri ve talep koşullarını belirleyen göstergelerden oluşmuştur. Bulgular özellikle uzun dönemde kurlardaki değişimin fiyatlar üzerine önemli derece de yansıdığını göstermiştir. Duasa (2009) reel döviz kur seviyesindeki değişimlerin ithalat ve ihracat fiyatları üzerindeki etkisini Malezya ekonomisi için araştırmıştır. Dışa açık küçük bir ekonomi olarak kur şoklarına Malezya ekonomisinin aşırı duyarlı olduğu varsayımından hareket edilmiştir. Vektör Hata Düzelme modeli kullanılarak (VECM) 1999 ile 2006 yılları arasındaki aylık verilerden yararlanılmıştır. Ampirik sonuçlar reel döviz kurundaki değişimlerin ithal ve ihraç fiyatlarını büyük oranda etkileyerek yurt içi fiyat seviyesine yansıdığını göstermiştir. Öte yandan, Beirme ve Bijsterbosch (2011) merkezi ve doğu Avrupa'da bulunan yedi ülkede kur geçişkenliği sürecini analiz etmişlerdir. Çalışmada VAR ve VECM Modelleri kullanılarak 1995 ile 2008 yılları arasındaki veriler incelenmiştir. Tüketici fiyatları, üretici fiyatları, petrol fiyatları, nominal kur değerleri ve endüstriyel üretim göstergeleri değişken olarak kullanılmıştır. Bulgular kur geçişkenliği sürecinin farklı oranlarda da olsa yaşandığını ortaya koymuştur. Ülkeler arasında kur geçişkenliğinin dercesine ilişkin yaşanan farklılıkların ise ülkelerde izlenen farklı döviz kuru rejiminden kaynaklandığı belirlenmiştir. Jimborean (2013) merkezi ve doğu Avrupa'da bulunan on ülkede kur seviyesindeki değisşimlerin fiyatlar üzerine etkisini analiz etmiştir. Çalışmada dinamik panel veri analizi yöntemi kullanılmış ve bu şekilde 1996 ile 2011 yılları arasındaki çeyreklik verilerden yararlanılmıştır. Kur değişimlerin en büyük etkiyi önce ithal fiyatları üzerinde daha sonra da üretici ve tüketici fiyatları üzerinde oluşturduğu belirlenmiştir. Son olarak Shaikh ve Hussain (2015) döviz kuru geçişkenliği sürecini Pakistan ekonomisi için 2005 ile 2011 yılları arasındaki dönemde yer alan aylık verileri 
Karahan, Ö., Gencür, A., S., / Journal of Yasar University, 2020, Special Issue on 3rd International EUREFE Congress, $48-65$

kullanarak VAR yöntemi ile analiz etmişlerdir. Ampirik bulgular kur geçişkenliğinin üretici fiyatlarına daha yüksek, tüketici fiyatlarına ise daha düşük derecede yansıdığını göstermiştir

Döviz kuru geçişkenliğinin analizine ilişkin olarak Türkiye ekonomisi üzerinde de önemli sayıda çalışmanın gerçekleştirildiği görülmektedir. Değişik yöntemler kullanılarak farklı dönemlere ilişkin yapılan bu çalışmalarda genel olarak kur geçişkenliğinin varlığ tespit edilmiştir. Işık ve Işık (2004) Türkiye'de döviz kuru ve enflasyon değişkenleri arasında eşbütünleşik bir durum olup olmadığını araştırmışlardır. Bunun için 1982 ile 2003 yılları arasındaki çeyrek dönemlik veriler analiz edilmiştir. Ekonometrik yöntem olarak Johansen Çoklu Eşbütünleşme Yöntemi kullanılmıştır. Analiz sonuçları döviz kuru ile enflasyon arasında uzun dönemli bir etkileşim olduğunu göstermiştir. Özçiçek (2007) Türkiye'de kur değişimlerinin toptan ve tüketici fiyatları üzerine etkisini incelemişlerdir. Bunun için 1982 ile 2002 yılları arasındaki aylık veriler VAR modeli ile analiz edilmiştir. Çalışmada ekonometrik yöntem olarak VAR modeli kullanılmıştır. Yapılan analiz sonuçlarına göre Türkiye'de yaşanan yüksek kur geçişkenliğinin özellikle 1994 ve 2001 yıllarında yaşanan krizlerinden kaynaklandığı bulunmuştur. Peker ve Görmüş (2008) Türkiye'de döviz kurunun enflasyonist etkilerini 1987 ile 2006 dönemi içinde VAR yöntemini kullanarak incelemişlerdir. Sonuçlar Türkiye' de fiyatlar genel düzeyinde ortaya çıkan değişmelerin döviz kuru hareketlerine oldukça duyarlı olduğunu ortaya koymuştur.

Son dönemde Türkiye üzerine gerçekleştirilen çalışmalarla ilgili olarak, Dedeoğlu ve Kaya (2014) döviz kuru geçişkenliği sürecini 1995 ile 2012 yılları arasındaki aylık veriler için VAR yöntemi kullanarak analiz etmiştir. Sonuçlar kur geçişkenliğinin tüketici fiyatları yerine daha çok üretici fiyatları üzerinde etkili olduğunu göstermiştir. Ayrıca Türkiye'nin enflasyon hedeflemeli istikrar programına geçmesi ile birlikte kurların fiyatlar üzerindeki etkisinin hızla azaldığııı göstermiştir. Ergin (2015) Türkiye'de döviz kuru ve enflasyon arasındaki ilişkiyi VAR analizi ile 2005 ile 2014 dönemleri içindeki aylık verileri kullanarak incelemiştir. Analiz sonucunda döviz kurunun enflasyon üzerinde yarattığı etkinin oldukça yüksek olduğu tespit edilmiştir. Ayrıca kur değişimlerinin ağırlıklı olarak ithalat fiyatları kanalı ile gerçekleştiği ortaya konmuştur. Son olarak Karahan (2017) kurlardaki değişimin tüketici fiyatları üzerinde yarattığı etkiyi Türkiye'de enflasyon hedeflemeli rejimin açık bir biçimde uygulanmaya başlandığ 2006 öncesi ve sonrasında analiz etmiştir. Bunun için 1995 ve 2000 ile 2006 ve 2014 yılları arasındaki aylık verileri Hata Düzeltme Modeli (Error Correction Model) çerçevesinde incelemiştir. Sonuçlar Türkiye'de 2006 yılından itibaren açık bir biçimde uygulanmış olan 
enflasyon hedeflemeli para programının kur geçişkenliğinin hem hızını hem de derecesini düşürdüğünü göstermiştir.

\section{Veri ve Ekonometrik Yöntem}

Çalışmamızda döviz kuru geçişkenliği süreci, kur değişimlerinin ithal girdi fiyatları üzerinden üretici fiyatlarına etkisi bağlamında, tahmin edilmiştir. Bu çerçevede nominal kur seviyesi, genel ithalat birim değer endeksi ve genel üretici fiyat endeksi verileri kullanılmıştır. Dış Ticarette kullanılan para birimleri içinde en çok kullanılan ABD doları ve Avrupa para birimi Euro olduğu için, Nominal kur (NKUR), aylık ortalama nominal efektif ABD Doları / Türk Lirası kuru ile nominal efektif Euro / Türk Lirası kurunun aritmetik ortalaması hesaplanarak elde edilmiştir. Genel İthalat Birim Değer Endeksi değişkeni (PMGEN), ithalat fiyatlarını temsil etmesi amacıyla kullanılmıştır. Kur geçişkenliği mekanizmasının işleyişini tespit edebilmek için TL cinsinden hesaplanmıştır. Genel Üretici Fiyat Endeksi (UFEGEN) değişkeni, yerel fiyatları temsil etmesi amacıyla kullanılmıştır. Her iki endeks değeri için 2010 yıllı temel yıl olarak ele alınmıştır. Nominal kur verisi Türkiye Cumhuriyeti Merkez Bankası'na ait Elektronik Veri Dağıtım Sistemi (EVDS)'nden elde edilmiştir. Diğer veriler ise Türkiye İstatistik Kurumu'nun veri tabanından sağlanmıştır. Sözü edilen bütün değişkenler logaritmaları alınarak analize katılmıştır.

Araştırmada kur (NKUR) değişimlerinin genel ithalat birim değer endeksi (PMGEN) üzerinden tüketici fiyat endeksini (UFEGEN) nasıl etkilediği araştırılmıştır. Her ne kadar kullanılan ampirik yöntemde bir ndenesllik kısıtı ortaya konmasa dahi değişkenler arasındaki ilişkinin aşağıda belirlendiği şekilde gerçekleşmesi beklenmektedir.

\section{NKUR $\uparrow \rightarrow$ PMGEN $\uparrow \rightarrow$ UFEGEN $\uparrow$}

Ampirik analiz yöntemi olarak Sims (1980) tarafından ortaya konan Vektör Otoregresif (Vector Autoregressive -VAR) yaklaşımı çerçevesinde geliştirilen Etki-Tepki Fonksiyonu (Impulse-Response Function) ve Varyans Ayrıştırması (Variance Decomposition) tekniklerinden yararlanılmıştır. Bu yaklaşımda oluşturulan VAR modelinin tahmin edilmesi sonucu elde edilen artıkların iki farklı teknikle analiz edilmesiyle söz konusu değişkenler arasındaki ilişkilerin niteliği hakkında yorumlar yapılmaktadır. Buna göre, Etki-Tepki Analizi çerçevesinde tahmin edilen VAR modeli hata terimi değerlerindeki bir birimlik değişikliğin modeldeki diğer değişkenlerin hata terim değerlerindeki tepkileri üzerinden 
değerlendirilmektedir. Öte yandan, Varyans Ayrıştırması tekniğinde ise veri bir zaman aralığında değişkenlerden birinin hata teriminde meydana gelen bir şok nedeniyle diğer değişkenin hata terimindeki yüzde değişimler ortaya konarak çıkarımlarda bulunulmaktadır. Sonuçta bu teknikler sayesinde model içindeki değişkenler arasındaki bağlantılar her hangi bir teorik kısıtlmaya tabi tutulmadan analiz edilerek, söz konusu değişkenler arasındaki nedenseliklik ilişkileri ortaya konmaktadır.

Yukarıda belirlenen ampirik metodoloji çerçevesinde tahmin edilen ekonometrik model aşağıdaki gibi belirlenebilir.

$$
\begin{aligned}
& \text { NKUR }_{\mathrm{t}}=\mathrm{E}_{\mathrm{t}-1}\left[\mathrm{NKUR}_{\mathrm{t}}\right]+\varepsilon_{\mathrm{t}}^{\mathrm{NKUR}} \\
& \text { PMGEN }_{\mathrm{t}}=\mathrm{E}_{\mathrm{t}-1}\left[\mathrm{PMGEN}_{\mathrm{t}}\right]+\alpha_{1} \varepsilon_{\mathrm{t}}^{\mathrm{NKUR}}+\varepsilon_{\mathrm{t}}^{\text {PMGEN }} \\
& \text { UFEGEN }_{\mathrm{t}}=\mathrm{E}_{\mathrm{t}-1}\left[\mathrm{UFEGEN}_{\mathrm{t}}\right]+\delta_{1} \varepsilon_{\mathrm{t}}^{\mathrm{NKUR}}+\delta_{2} \varepsilon_{\mathrm{t}}^{\text {PMGEN }}+\delta_{3} \varepsilon_{\mathrm{t}}^{\text {UFEGEN }}
\end{aligned}
$$

Eşitliklerde $\varepsilon_{t}^{N K U R}$ nominal döviz kuru şokunu, $\varepsilon_{t}^{P M G E N}$ genel ithalat birim değer endeksinde oluşan şoku, $\varepsilon_{t}^{U F E G E N}$ ise genel üretici fiyat endeksi şokunu temsil etmektedir.

\section{Ampirik Sonuçlar}

Araştırma kapsamında ampirik analiz yapılabilmesi için verilerin durağanlıklarının birim kök testler ile belirlenmesi oldukça önemlidir. Bunu için çalışımızda kullanılan Nominal Kur (NKUR), Genel İthalat Birim Değer Endeksi (PMGEN) ve Genel Üretici Fiyat Endeksi (UFEGEN) değişkenlerinin durağanlıkları sırası ile Dickey and Fuller (1981) ve Phillips ve Perron (1988) tarafından geliştirilen Genişletilmiş Dickey-Fuller (Augmented Dickey FullerADF) ve Phillips-Perron (Phillips Perron-PP) birim kök testi uygulanarak belirlenmiştir. Buna göre elde edilen birim kök test sonuçları Tablo 1' de sunulmuştur. Görüldüğü gibi bütün değişkenlerin, logaritmaları alındıktan sonra, düzey değerinde durağan olmadığı dolayısıyla birim kök içerdiği tespit edilmiştir. Ancak bütün değişkenlerin logaritmik değerlerinin birinci farkı alınarak birim kök testi uygulandığında \%1 anlamlılık düzeyinde durağan oldukları görülmüştür. 
Karahan, Ö., Gencür, A., S., / Journal of Yasar University, 2020, Special Issue on 3rd International EUREFE Congress, $48-65$

Tablo 1. Birim Kök Testi Sonuçları

\begin{tabular}{|c|c|c|c|c|}
\hline \multirow{2}{*}{ Değişken } & \multicolumn{2}{|c|}{ ADF } & \multicolumn{2}{c|}{ PP } \\
\cline { 2 - 5 } & Seviye & 1. Fark & Seviye & 1 . Fark \\
\hline NKUR & -2.2011 & $-9.1444^{*}$ & -1.7834 & $-8.9439^{*}$ \\
\hline UFEGEN & -2.8095 & $-7.3514^{*}$ & -2.8796 & $-7,2672^{*}$ \\
\hline PMGEN & -2.2631 & $-9.5677^{*}$ & -2.8387 & $-9.5990^{*}$ \\
\hline
\end{tabular}

Not: * simgesi \%1 seviyesinde anlamlllı̆̆l göstermektedir.

Değişkenlerin aynı derecede durağan oldukları belirlendikten sonra VAR modeli çerçevesinde analizin gerçekleştirilebilmesi için uygun gecikme uzunluklarının bulunması gerekmektedir. Çeşitli bilgi kriterlerine göre belirlenmiş uygun gecikme sayısı Tablo 2'de gösterilmiştir. FPE ve AIC'nin gösterdiği 3, SC'nin ve HQ'nin gösterdiği 1 gecikme sayıları modelde test edildiğinde otokorelasyon ve değişen varyans sorunuyla karşılaşılmıştır. Olabilirlik Oranı LR Test Kriterinin gösterdiği 12 gecikme sayısı model için uygun gecikme uzunluğu olarak tespit edilmiştir.

Tablo 2. Modelin Bilgi Kriterlerine Göre Uygun Gecikme Sayısının Analizi

\begin{tabular}{|c|c|c|c|c|c|c|}
\hline Gecikme & Log $L$ & LR & FPE & AIC & SC & HQ \\
\hline 0 & 1061.952 & NA & $1.91 \mathrm{e}-11$ & -16.16721 & -16.10137 & -16.14046 \\
\hline 1 & 1093.427 & 61.02804 & $1.36 \mathrm{e}-11$ & -16.51034 & $16.24697 *$ & $16.40332 *$ \\
\hline 2 & 1107.417 & 26.48467 & $1.26 \mathrm{e}-11$ & -16.58652 & -16.12561 & -16.39924 \\
\hline 3 & 1121.788 & 26.54808 & $1.16 \mathrm{e}-11 *$ & $16.66852 *$ & -16.01008 & -16.40097 \\
\hline 4 & 1128.321 & 11.76822 & $1.20 \mathrm{e}-11$ & -16.63085 & -15.77488 & -16.28303 \\
\hline 5 & 1134.735 & 11.26156 & $1.25 \mathrm{e}-11$ & -16.59137 & -15.53787 & -16.16329 \\
\hline 6 & 1143.913 & 15.69379 & $1.25 \mathrm{e}-11$ & -16.59409 & -15.34305 & -16.08574 \\
\hline
\end{tabular}


Karahan, Ö., Gencür, A., S., / Journal of Yasar University, 2020, Special Issue on 3rd International EUREFE Congress, $48-65$

\begin{tabular}{|c|c|c|c|c|c|c|}
\hline 7 & 1149.704 & 9.636215 & $1.32 \mathrm{e}-11$ & -16.54509 & -15.09652 & -15.95647 \\
\hline 8 & 1162.031 & 19.94987 & $1.26 \mathrm{e}-11$ & -16.59589 & -14.94979 & -15.92701 \\
\hline 9 & 1164.536 & 3.938715 & $1.40 \mathrm{e}-11$ & -16.49673 & -14.65309 & -15.74758 \\
\hline 10 & 1171.869 & 11.19633 & $1.45 \mathrm{e}-11$ & -16.47129 & -14.43012 & -15.64187 \\
\hline 11 & 1181.951 & 14.92940 & $1.44 \mathrm{e}-11$ & -16.48779 & -14.24909 & -15.57811 \\
\hline 12 & 1193.503 & $16.57941 *$ & $1.40 \mathrm{e}-11$ & -16.52677 & -14.09053 & -15.53682 \\
\hline
\end{tabular}

Uygun gecikme uzunluğu belirlendikten sonra bu gecikme uzunluğuna göre tahmin edilen VAR modeli çerçevesinde Etki-Tepki analizi yapılmıştır. Buna göre modelimizin elde edilen Etki Tepki Fonksiyon Grafikleri Şekil 1'de gösterilmiştir. Kur'un (NKUR) hem genel ithalat birim değer endeksi (PMGEN) hem de genel üretici fiyat endeksine (UFEGEN) karşı verdiği tepkiler, sıfır çizgisi ile belirlenen güven aralığının içinde kaldığı için, istatistiksel olarak anlamsızdır. Öte yandan PMGEN'in NKUR şokuna karşın ilk iki dönem pozitif tepki verdiği görülmektedir. UFEGEN şokuna karşı verdiği tepki ise istatistiki olarak anlamsızdır. UFEGEN, NKUR şokuna karşı ilk dönem pozitif tepki verirken, PMGEN şokuna karşı da aynı şekilde ikinci döneme kadar pozitif tepki vermektedir. Bu durum kur değişimlerinin hem doğrudan hem de modelimizde belirlendiği şekilde ithalat birim değer endeksi üzerinden genel üretici fiyat endeksini etkilediğini göstermektedir. Böylece, etki tepki fonksiyonlarına ait grafikler incelendiğinde, döviz kurunda meydana gelen değişmelerin üretici fiyatlarına ithalat birim değer endeksi üzerinden yansıması sürecinin varlığı ortaya çıkmaktadır. Başka bir ifade ile ithal girdi maliyetleri üzerinden döviz kuru geçişkenliği kanalının işlediği belirlenmektedir. 
Karahan, Ö., Gencür, A., S., / Journal of Yasar University, 2020, Special Issue on 3rd International EUREFE

NKUR'un NKUR'a

Tepkisi

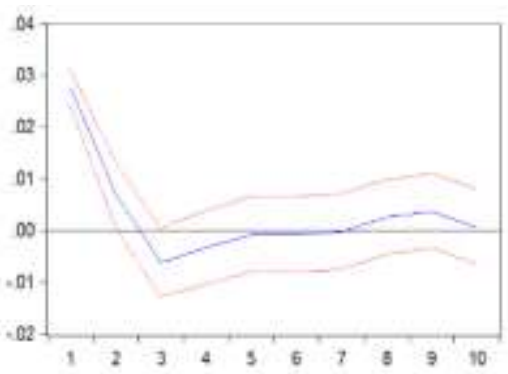

PMGEN'in NKUR'a

Tepkisi

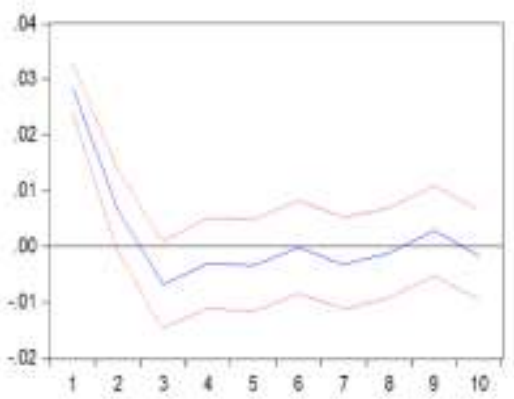

UFEGEN'in NKUR'a

Tepkisi

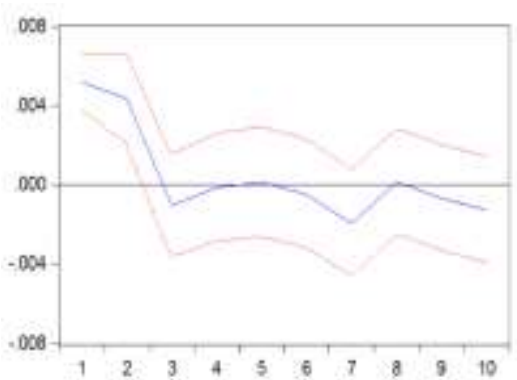

NKUR'un PMGEN'e

Tepkisi

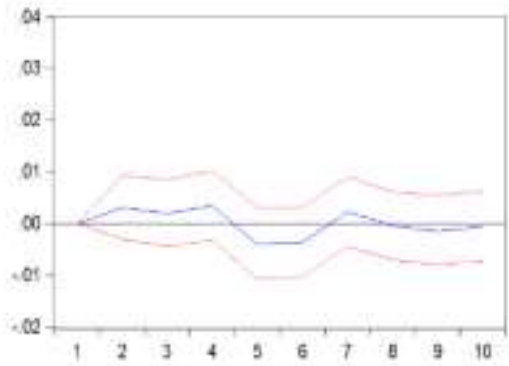

PMGEN'in PMGEN'e

Tepkisi

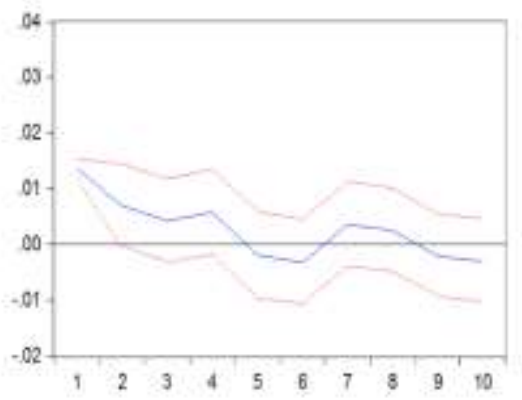

UFEGEN'in PMGEN'e

Tepkisi

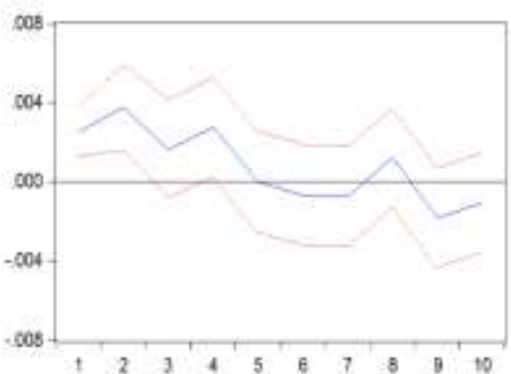

NKUR'un UFEGEN'e

Tepkisi

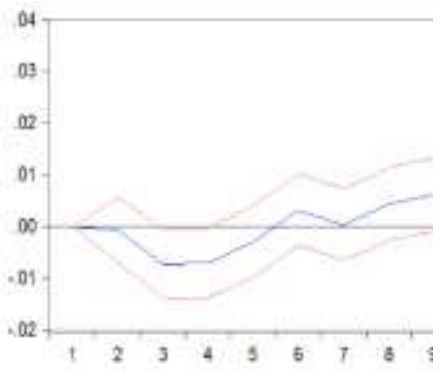

PMGEN'in UFEGEN'e Tepkisi

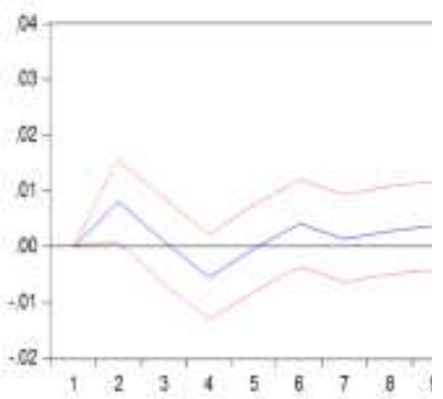

UFEGEN'in UFEGEN'e Tepkisi

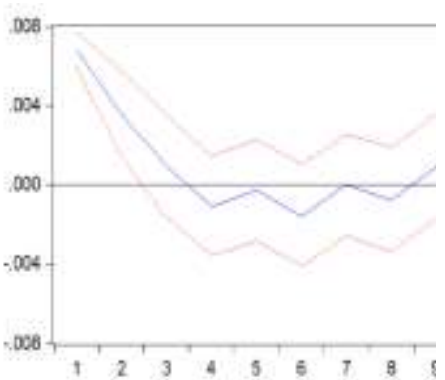

Şekil 1. Etki Tepki Fonksiyonları Grafiği

Çalışma kapsamında oluşturulan VAR modeli çerçevesinde Varyans Ayrıştırması analizi de yapılmış ve sonuçlar Tablo 3'te gösterilmiştir. NKUR' daki değişimler incelendiğinde, ilk ay 
Karahan, Ö., Gencür, A., S., / Journal of Yasar University, 2020, Special Issue on 3rd International EUREFE Congress, $48-65$

\%100' oranıyla başlayarak onuncu aya kadar gelişen süreçte \% 78,64 oranına kadar gerilese de kur seviyesindeki değişimlerin daha çok kendisi tarafından açıklandığı görülmektedir. Buna göre NKUR'un en dişsal değişken olduğunu sonucuna varılabilir. Öte yandan PMGEN'deki değişimlere bakıldığında en belirleyici etki NKUR tarafından gelmektedir. PMGEN birinci ayda \% 81.41'nin onuncu ayda ise \% 66.97 oranında NKUR tarafindan belirlenmektedir. Böylece NKUR'un PMGEN üzerinde önemli bir etkisinin olduğu görülmektedir. UFEGEN'inde meydana gelen değişimler incelendiğinde ise süreç içerisinde \% 33'lük bir ortalama oran ile NKUR'un büyük bir etkiye sahip olduğu belirlenmektedir. Öte yandan süreç içerisinde UFEGEN üzerinde hem NKUR hem de PMGEN'in etkisinin olduğu görülmektedir. NKUR'un etkisi birinci ayda \% 33.70 oranı ile başlayıp onuncu ayda \% 33.77 seviyesine ulaşmaktadır. PMGEN'nin etkisinin de zaman içinde artarak önemli bir seviyeye ulaşmaktadır. Buna göre PMGEN'in birinci ayda \% 8.11' olan etki oranı onuncu ayda \% 24,15 seviyesine ulaşmaktadır. Buna göre kurdan başlayarak ithal fiyatları kanalıyla üretici fiyatları üzerinde yaratılan etkiye ilişkin belirgin bir kanıt bulunmuştur. Böylece, tıpkı etki tepki fonksiyonu analizinde olduğu gibi, varyans ayrıştırması analizi de ampirik model çerçevesinde belirlenen ithal girdi maliyetleri üzerinden döviz kuru geçişkenliğinin Türkiye'de işlediğini göstermektedir.

Tablo 3. Varyans Ayrıştırması Analizi Sonuçları

\begin{tabular}{|c|c|c|c|c|}
\hline \multicolumn{5}{|c|}{ Döviz Kurunun Varyans Ayrıştırması (NKUR) } \\
\hline Dönem & $\begin{array}{c}\text { Standart } \\
\text { Hata }\end{array}$ & NKUR & PMGEN & TUFEGEN \\
\hline 1 & 0.027573 & 100.0000 & 0.000000 & 0.000000 \\
\hline 2 & 0.028713 & 98.74177 & 1.213163 & 0.045066 \\
\hline 3 & 0.030296 & 92.80842 & 1.549229 & 5.642350 \\
\hline 4 & 0.031471 & 87.06476 & 2.675392 & 10.25985 \\
\hline 5 & 0.031851 & 85.06382 & 4.097832 & 10.83835 \\
\hline 6 & 0.032223 & 83.15983 & 5.252295 & 11.58788 \\
\hline 7 & 0.032305 & 82.74116 & 5.718115 & 11.54073 \\
\hline & & & & \\
\hline
\end{tabular}


Karahan, Ö., Gencür, A., S., / Journal of Yasar University, 2020, Special Issue on 3rd International EUREFE Congress, $48-65$

\begin{tabular}{|c|c|c|c|c|}
\hline 8 & 0.032714 & 81.35584 & 5.592684 & 13.05148 \\
\hline 9 & 0.033544 & 78.66028 & 5.475545 & 15.86418 \\
\hline 10 & 0.033554 & 78.64533 & 5.491309 & 15.86337 \\
\hline \multicolumn{5}{|c|}{ Genel İthalat Birim Değer İndeksi Varyans Ayrıştırması (PMGEN) } \\
\hline Dönem & $\begin{array}{c}\text { Standart } \\
\text { Hata }\end{array}$ & NKUR & PMGEN & UFEGEN \\
\hline 1 & 0.031463 & 81.41429 & 18.58571 & 0.000000 \\
\hline 2 & 0.033841 & 74.24616 & 20.20724 & 5.546599 \\
\hline 3 & 0.034807 & 74.07971 & 20.60600 & 5.314289 \\
\hline 4 & 0.035847 & 70.58232 & 21.96019 & 7.457494 \\
\hline 5 & 0.036073 & 70.64074 & 21.98373 & 7.375539 \\
\hline 6 & 0.036436 & 69.24387 & 22.31441 & 8.441719 \\
\hline 7 & 0.036778 & 68.70706 & 22.86865 & 8.424294 \\
\hline 8 & 0.036988 & 68.05098 & 23.06004 & 8.888979 \\
\hline 9 & 0.037338 & 67.35152 & 22.93481 & 9.713674 \\
\hline 10 & 0.037509 & 66.97338 & 23.38100 & 9.645619 \\
\hline \multicolumn{5}{|c|}{ Genel ÜFE İndeksinin Varyans Ayrıştırması (UFEGEN) } \\
\hline Dönem & $\begin{array}{c}\text { Standart } \\
\text { Hata }\end{array}$ & NKUR & PMGEN & UFEGEN \\
\hline 1 & 0.008936 & 33.70220 & 8.115708 & 58.18209 \\
\hline 2 & 0.011202 & 36.38863 & 16.35070 & 47.26067 \\
\hline 3 & 0.011411 & 35.90436 & 17.85984 & 46.23580 \\
\hline
\end{tabular}


Karahan, Ö., Gencür, A., S., / Journal of Yasar University, 2020, Special Issue on 3rd International EUREFE Congress, $48-65$

\begin{tabular}{|c|c|c|c|c|}
\hline 4 & 0.011788 & 33.65763 & 22.19054 & 44.15182 \\
\hline 5 & 0.011792 & 33.64846 & 22.17389 & 44.17765 \\
\hline 6 & 0.011927 & 33.06467 & 22.01592 & 44.91942 \\
\hline 7 & 0.012106 & 34.65132 & 21.74949 & 43.59919 \\
\hline 8 & 0.012194 & 34.16900 & 22.44622 & 43.38478 \\
\hline 9 & 0.012384 & 33.44221 & 23.95143 & 42.60636 \\
\hline 10 & 0.012512 & 33.77895 & 24.15403 & 42.06703 \\
\hline
\end{tabular}

Buraya kadar elde edilen ampirik sonuçların güvenirliliği ancak kullanılan modelin bazı ekonometrik testler ile sınanması yolu ile sağlanabilir. Bu çerçevede ilk olarak değişkenlerin hata terimlerinin sabit varyansa sahip olup olmadığı araştırlmıştır. Tahmin edilen modelin hata terimlerinde değişen varyans olup olmadığının tespit edilmesi için White Değişen Varyans testi uygulanmıştır. White testi kapsamında otokorelasyonun yokluğunu iddia eden sıfır hipotezine karşı var olduğunu iddia eden alternatif hipotez test edilmektedir. Tablo 4'deki White Testi sonuçlarına bakıldığında olasılık değerinin \%5'ten büyük olması nedeniyle $H_{0}$ hipotezi reddedilemez. $\mathrm{Bu}$ durumda hata teriminde değişen varyans yoktur. Hata terimleri sabit varyanslıdır ve VAR modelinin koşullarından olan sabit varyanslı olma koşulu sağlanmıştır.

Tablo 4. White Testi Değişen Varyans Analizi Sonuçları

\begin{tabular}{|c|c|c|}
\hline Ki-Kare & df & Olasilik \\
\hline 608.8595 & 612 & 0.5282 \\
\hline
\end{tabular}

Tahmin edilen VAR modelinden elde edilen sonuçlarının güvenilir olabilmesi için, aynı zamanda modele ait karakteristik polinom köklerinin birim çember içerisinde yer alıp almadığının tespit edilmesi gerekmektedir. Polinom köklerinin hepsi birim çemberin içinde olması durumunda VAR modelinin istikrarlı ve durağan olduğu varsayımı sağlanmış olmaktadır. Karakteristik polinom kökleri grafiği Şekil 2'de gösterilmiştir. Buradan görüldüğü 
gibi karakteristik polinom kökleri birim çemberin içinde yer almaktadır. Dolayısı ile bu durum modelin istikrarlı olduğunu açıkça ortaya koymaktadır. Bunun için kullanılan ampirik modelden tahmin elde edilen etki tepki fonksiyonu ve varyans ayrıştırması sonuçları güvenilirdir.

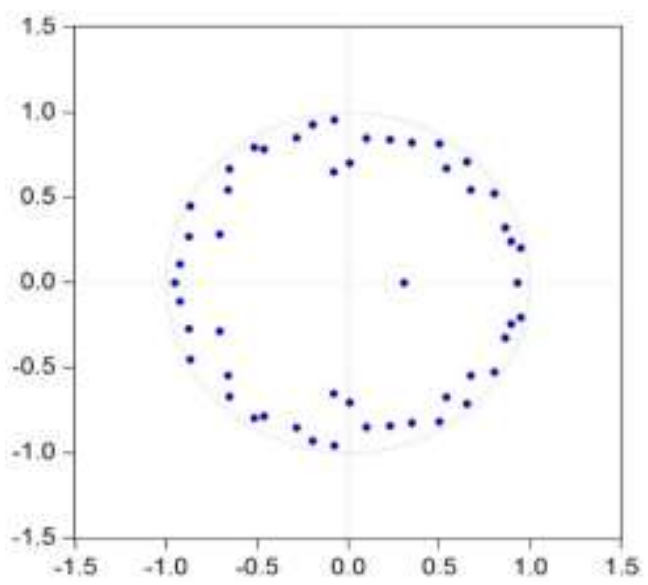

Şekil 2. Karakteristik Polinom Kökleri Grafiği

Son olarak tahmin edilen modele ait hata terimi varsayımlarından otokorelasyon olup olmadığının tespit edilmesi gerekmektedir. Bu varsayımın sağlanıp sağlanmadığı LM testi ile belirlenebilmektedir. LM testi çerçevesinde otokorelasyonun yokluğunu iddia eden sıfır hipotezine karşı var olduğunu iddia eden alternatif hipotez sınanmaktadır. Buna göre gerçekleştirilen modele ait otokorelasyon testi sonuçları Tablo 5'de sunulmuştur. Tablodaki bütün olasılık değerleri \%5 den büyüktür. Böylece $H_{0}$ Hipotezi reddedilemez. Bu durumda elde edilen sonuçlar hata teriminde otokorelasyonun olmadığını açıkça ortaya koymaktadır.

Tablo 5. Lagrange Çarpan Testi Otokorelasyon Analizi Sonuçları

\begin{tabular}{|c|c|c|}
\hline Gecikme & LM istatistiği & Olas1lik \\
\hline 1 & 3.761527 & 0.9264 \\
\hline 2 & 7.338617 & 0.6019 \\
\hline 3 & 9.07841 & 0.4301 \\
\hline 4 & 13.68088 & 0.1341 \\
\hline 5 & 11.22347 & 0.2607 \\
\hline
\end{tabular}




\begin{tabular}{|c|c|c|}
\hline 6 & 11.26478 & 0.258 \\
\hline 7 & 16.38504 & 0.0593 \\
\hline 8 & 8.617692 & 0.4733 \\
\hline 9 & 8.661553 & 0.4691 \\
\hline 10 & 6.386118 & 0.7007 \\
\hline 11 & 7.388028 & 0.5968 \\
\hline 12 & 3.843311 & 0.9214 \\
\hline
\end{tabular}

\section{Sonuç}

Türkiye de fiyat istikrarını sağlamak amacı ile 2006 yılından itibaren açık bir biçimde Enflasyon Hedeflemeli Para Programı uygulanmaktadır. Bu program çerçevesinde, döviz kuru serbest dalgalanmaya bırakılarak, sadece faiz politikası toplam talebi kontrol etmek için kullanılmaktadır. Böylece, kur geçişkenliği olgusundaki gelişmeler Türkiye'de uygulanan enflasyon hedeflemeli politikaların etkinliği açısından büyük önem taşımaktadır. Buradan hareketle çalışmamızda döviz kuru geçişkenliği süreci analiz edilerek uygulanmakta olan Enflasyon Hedeflemeli İstikrar Politikalarının etkinliğine ilişkin yarattığı riskler araştırılmıştır. Bu kapsamda, Türkiye'de 2006 ile 2017 yılları arasındaki dönem için, kur değişimlerinin ithal girdi maliyetleri yolu ile üretici fiyatları üzerinde yarattı̆̆ı etkiler, VAR yöntemi kullanılarak, analiz edilmiştir. Sonuçlar Türkiye de kur değişimlerinin ithal ürün değerini dalgalandırarak doğrudan Üretici Fiyat Endeksi üzerinde etki yarattığını göstermektedir. Bu durum Türkiye'de gerçekleştirilen ithalatın büyük kısmının ara ve sermaye malına dayalı olmasından kaynaklanmaktadır. Ülkedeki üretim yapısının dış ara ve sermaye malına bağımlı olması kur değişimlerinin ithalat birim değer endeksi üzerinden Üretici Fiyat Endeksini etkilemesine yol açmaktadır.

Araştırma sonucunda elde dilen bulgular Türkiye'de yaşanan enflasyonun dinamikleri ve Merkez Bankası tarafından uygulanan para politikasının etkinliği açısından önemli çıkarımlar ortaya koymaktadır. Buna göre Türkiye'de üretim yapısının dış girdiye bağımlı olması kurdaki değişimlerin üretim maliyetleri yolu ile enflasyon üzerinde büyük bir etkiye sahip olmasına neden olmaktadır. Bu yüzden, öncelikli olarak uygulanacak yapısal politikalar ile üretim yapısının ithal girdiye bağımlılığı azaltılmalıdır. Öte yandan, Türkiye'de Merkez Bankasının 
Karahan, Ö., Gencür, A., S., / Journal of Yasar University, 2020, Special Issue on 3rd International EUREFE Congress, $48-65$

kurları tamamı ile serbest dalgalanmaya bırakarak fiyat istikrarını sağlaması mümkün değildir. Başka bir ifade ile merkez bankası toplam talebi kontrol altına almak için sadece politika faizini kullanarak kur değişimlerine kayıtsız kalmamalıdır. Politika yapıcılar, enflasyon hedeflemeli para politikası çerçevesinde kullandıkları uygulama seti içerisinde mutlaka döviz kurundaki meydana gelecek değişmeleri kontrol altına alacak araçlara sahip olmalıdır. Bu bağlamda, özellikle kısa vadeli yabancı sermaye hareketlerindeki hızlı değişimin yaratacağı döviz kuru dalgalanmalarının kontrol edilmesi, yurt içi fiyat istikrarının sağlanması için büyük önem taşımaktadır. 
Karahan, Ö., Gencür, A., S., / Journal of Yasar University, 2020, Special Issue on 3rd International EUREFE Congress, 48-65

\section{KAYNAKÇA}

An, L. 2006. "Exchange Rate Pass-Through: Evidence Based on Vector Autoregression with Sign Restrictions". University Library of Munich, Germany, MPRA Paper, No: 527.

Barhoumi, K. 2006. "Differences in Long Run Exchange Rate Pass-Through into Import Prices in Developing Countries: An Empirical Investigation”. Economic Modelling, 23(6), 926-951.

Bailliu, J., \& Fujii, E. 2004. "Exchange Rate Pass-Through and the Inflation Environment in Industrialized Countries: An Empirical Investigation". Bank of Canada Banque du Canada Working Paper, No: 200421.

Beirme, J., \& Bijsterbosch, M. 2011. "Exchange Rate Pass-Through in Central and Eastern European EU Member States”. Journal of Policy Modelling, 33(2), 241-254.

Campa J. M. \& Goldberg L. S. 2002. "Exchange Rate Pass-Through into Import Prices: A Macro or Micro Phenomenon?" NBER Working Paper, No: 8934.

Dedeoglu, D \& Kaya, H. 2014. "The Evolution of Exchange Rate Pass-Through in Turkey: Does Inflation Targeting Matters? Afro Eurasian Studies Journal, 3(1), 26-33.

Dickey, D. A., \& Fuller, W. A. 1981. "Distribution of the Estimators for Autoregressive Time Series with a Unit Root". Econometrica, 49, 1057-1072.

Duasa, J. 2009. "Exchange Rate Shock on Malaysian Prices of Import and Export: An Empirical Analysis". Journal of Economic Cooperation and Development. 30(3), 99-114.

Ergin, A. 2015. "Döviz Kuru ve Enflasyon Arasındaki Geçiş Etkisi: Türkiye Örneği”". Nĭğde Üniversitesi, I.I.I.B.F. Dergisi, 8(3), 13-29.

Işık, N. Acar, D. \& Işık, H. 2004. “Enflasyon ve Döviz Kuru İlişkisi: Bir Eşbütünleşme Analizi”. Süleyman Demirel Üniversitesi İktisadi ve İdari Bilimler Fakültesi Dergisi, 9(2), 325-340.

Jimborean, R. 2013. "The Exchange Rate Pass-Through in the New EU Member States”. Economic Systems, 37, 302-329.

Karahan, Ö. 2017. "Exchange Rate Pass-Through in Turkey before and After the Adoption of Inflation Targeting Regime". Financial Assets and Investing, 8(2), 37-48.

Kiliç R. 2016. "Regime-dependent Exchange-Rate Pass-Through to Import Prices". International Review of Economics and Finance, 41, 295-308.

Liu, Y. \& Liu, J. (2014). “Asymmetric Effects of Exchange Rate Pass-Through: An Empirical Analysis among China, the United States and Japan”. Computer Modelling \& New Technologies, 18(7), 204-211.

Özçiçek, Ö. 2007. “Türkiye'de Ekonomik Krizler Ve Döviz Kuru Enflasyon İlişkisi”. Gazi Üniversitesi İktisadi ve İdari Bilimler Fakültesi Dergisi, 9(1), 71 - 80.

Peker, O. \& Görmüş, Ş. 2008. “Türkiye'de Döviz Kurunun Enflasyonist Etkileri”. Süleyman Demirel Üniversitesi Iktisadi ve İdari Bilimler Fakültesi Dergisi, 13(2), 187-202.

Phillips, P. C., \& Perron, P. 1988. "Testing for a Unit Root in Time Series Regression”. Biometrika, 75, 335-346.

Shaikh, F.A., \& Hussain, S.M. 2015. "Exchange Rate Pass-Through to Domestic Prices: Evidence from Pakistan". Journal of Management Research, 2(1), 22-35.

Sims, C.A. 1980. "Macroeconomics and Reality". Econometrica, (48), 1- 48. 